\title{
The effectiveness of enhanced cognitive behavioural therapy in an outpatient setting
}

\author{
Rachel Signorini ${ }^{1 *}$, Jeanie Sheffield ${ }^{1}$, Natalie Rhodes ${ }^{2}$, Carmel Fleming $^{2}$, Warren Ward ${ }^{2}$ \\ From 2015 ANZAED Conference: Riding the Waves to Recovery \\ Surfers Paradise, Australia. 21-22 August 2015
}

The Eating Disorders Outreach Service (EDOS) at the Royal Brisbane and Women's Hospital has offered Enhanced Cognitive Behaviour Therapy (CBT-E) since 2009. The current research aimed to evaluate the effectiveness of the EDOS CBT-E program by analysing the outcome data of 114 adult outpatients (Mage $=26.06$ years, $\mathrm{SD}=8.35$ ) with a DSM-IV diagnosis of Anorexia Nervosa, Bulimia Nervosa, or Eating Disorder Not Otherwise Specified. Outpatients attended an average of 20-40 individual sessions with a psychologist or psychiatric registrar. Of those who commenced CBT-E, only 50\% completed treatment. Although a higher proportion of non-completers had an Axis II diagnosis, regression analyses revealed that the only significant predictor of drop-out from treatment was the presence of Axis IV psychosocial and environmental problems. Amongst those who completed treatment, CBT-E resulted in statistically and clinically significant improvements in eating disorder and general psychopathology, which were maintained at the 20-week followup. When the total sample, including non-completers was considered, statistically (and some clinically) significant improvements in eating disorder and general psychopathology were observed. The findings indicate that CBT-E is an effective treatment for adults with all eating disorders within outpatient settings. However, the high attrition observed indicates that strategies need to be identified to minimise drop-out.

\section{Authors' details}

'The University of Queensland, St Lucia, QLD, Australia. ${ }^{2}$ Eating Disorders Outreach Service, Herston, QLD, Australia.
Published: 23 November 2015

doi:10.1186/2050-2974-3-S1-03

Cite this article as: Signorini et al:: The effectiveness of enhanced

cognitive behavioural therapy in an outpatient setting. Journal of Eating Disorders 2015 3(Suppl 1):O3.

* Correspondence: rachel.signorini@uqconnect.edu.au

${ }^{1}$ The University of Queensland, St Lucia, QLD, Australia

Full list of author information is available at the end of the article

Submit your next manuscript to BioMed Central and take full advantage of:

- Convenient online submission

- Thorough peer review

- No space constraints or color figure charges

- Immediate publication on acceptance

- Inclusion in PubMed, CAS, Scopus and Google Scholar

- Research which is freely available for redistribution
() Biomed Central 